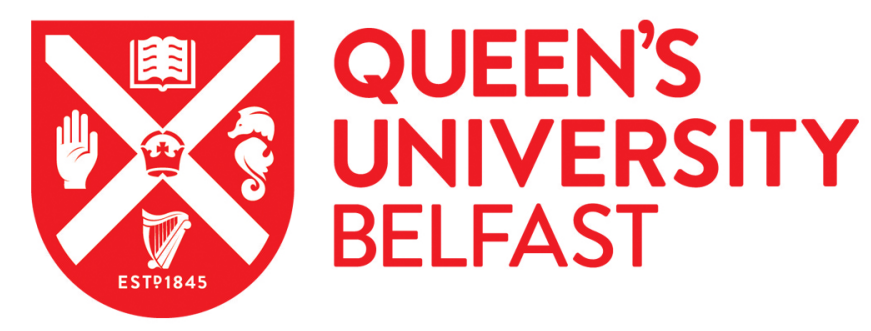

\title{
Developing a national standard for midwifery mentorship in Uganda
}

Kemp, J., Bannon, E. M., Muwema Mwanja, M., \& Tebuseeke, D. (2018). Developing a national standard for midwifery mentorship in Uganda. International Journal of Health Governance, 23(1), 81 -94.

https://doi.org/10.1108//JHG-09-2017-0051

Published in:

International Journal of Health Governance

Document Version:

Peer reviewed version

Queen's University Belfast - Research Portal:

Link to publication record in Queen's University Belfast Research Portal

Publisher rights

(c) 2018 Emerald Publishing Limited. This work is made available online in accordance with the publisher's policies. Please refer to any applicable terms of use of the publisher.

\section{General rights}

Copyright for the publications made accessible via the Queen's University Belfast Research Portal is retained by the author(s) and / or other copyright owners and it is a condition of accessing these publications that users recognise and abide by the legal requirements associated with these rights.

Take down policy

The Research Portal is Queen's institutional repository that provides access to Queen's research output. Every effort has been made to ensure that content in the Research Portal does not infringe any person's rights, or applicable UK laws. If you discover content in the Research Portal that you believe breaches copyright or violates any law, please contact openaccess@qub.ac.uk. 
Developing a national standard for midwifery mentorship in Uganda

Title: Developing a national standard for midwifery mentorship in Uganda

\section{Abstract:}

\section{Purpose}

This paper describes the development of a national standard for midwifery mentorship in Uganda, part of a wider quality improvement project which aimed to develop a model of mentorship for Ugandan Midwifery using the principles of action research. It aims to stimulate debate about strengthening the capacity of a health regulatory body, midwifery twinning partnerships and the use of international health volunteer placements.

\section{Methodology}

MOMENTUM was a 20 month project implemented by the Royal College of Midwives UK (RCM) and the Uganda Private Midwives Association (UPMA). Following a situational analysis, the project was structured around 3 action reflection/quality improvement cycles, participatory workshops, individual twinning relationships between UK and Ugandan midwives and peer exchange visits. The capacity of the Ugandan Nurses and Midwives Council (UNMC) to develop a standard for midwifery mentorship was assessed. A capacity building programme was then designed and implemented to develop the standard for midwifery mentorship.

\section{Findings}

The capacity of UNMC was increased and the standard was developed though has yet to be validated and adopted. However, this intervention may not be replicable as a stand-alone intervention because its success was inextricably linked to the wider programme activities and support structures.

\section{Practical Implications:}

Action research, midwifery twinning partnerships and targeted international health volunteer placements can be effective for designing and delivering complex health system changes, for implementing quality improvement, for delivering capacity building initiatives and for facilitating leadership development.

\section{Originality/Value}


Developing a national standard for midwifery mentorship in Uganda

This is the first paper describing midwifery twinning to strengthen the capacity of a regulatory body to develop practice standards.

Keywords: Midwifery, Quality improvement, action research, capacity building, health professional regulation, Midwifery twinning

Paper type: Research 
Developing a national standard for midwifery mentorship in Uganda

\section{Background}

\section{Midwifery in Uganda}

Investment in quality midwifery is imperative for the prevention of maternal and newborn deaths (Lancet, 2014; WHO, 2014). However, in Uganda, only 27\% of women's sexual, reproductive, maternal and newborn health needs are currently being met (UNFPA, 2014). Maternal and newborn mortality rates are high, there are too few midwives and the quality of midwifery care is variable (UNFPA, 2014; Nabiyre et al, 2014). Maternity care takes place in government, faith-based and private settings and quality is variable (Ministry of Health of Uganda, 2013). Worldwide there is continued need for quality midwifery education and competent practitioners (WHO, 2016) yet midwifery education in Uganda is varied in quality and does not always produce practitioners who are fit for practice at the point of registration (Nabirye, 2014; RCM, 2015). Student midwives report lack of hands-on clinical experience and support with learning in clinical practice (RCM, 2015a). The Uganda Nurses and Midwives Council was established in 1922 and has benefitted from considerable external support but, in 2015 , had limited capacity to set standards for quality care (RCM, 2016).

\section{Professional Association Twinning}

The International Confederation of Midwives (ICM) suggests that there are three pillars of a strong midwifery profession: education, regulation and professional association (ICM, 2014). It promotes twinning partnerships between professional midwives' associations for mutual benefit and organisational strengthening (ICM, 2014). Twinning is described as a cross-cultural, reciprocal process where two groups of people work together to achieve joint goals and is an example of an innovative approach that may enable attainment of Sustainable Development Goal 3, the promotion of well-being for all (Cadee, 2016). The Royal College of Midwives UK (RCM) and the Uganda Private Midwives Association (UPMA) have had a long-term twinning partnership since 2012 and jointly delivered the Global Midwifery Twinning Project (GMTP) (RCM, 2015b) between 20122015, funded by UK-Aid and The Tropical Health and Education Trust (THET) through the Health Partnership Scheme (HPS). During this project a strong relationship was formed with the Uganda Nurses and Midwives Council (UNMC), and other midwifery stakeholders through the placement of 26 UK midwife volunteers who implemented partnership development projects. There were also 3 exchange visits to the UK, 6 workshops and 11 visits of RCM staff/consultants to Uganda.

\section{Towards a project to strengthen midwifery mentorship}


Developing a national standard for midwifery mentorship in Uganda

A participatory midwifery needs assessment at the end of the GMTP identified poor support for student midwives' learning in clinical practice and a felt need for midwives to be trained as mentors (RCM, 2015a). Mentorship can prepare students to become competent and confident practitioners (Myall, Levet-Jones and Lathlean, 2008; Sayani et al, 2017) and mentorship has been found to improve the quality of clinical care, even in low-resource settings (Jayanna et al, 2016; Woekneh, G. et al, 2013). In 2014, as part of the GMTP, a pilot mentorship project, implemented by the Uganda Private Midwives Association in partnership with Kibuli School of Nursing and Midwifery, showed that student midwives reported significantly improved practice learning when supported by a mentor (RCM, 2015b). In 2015 the RCM/UPMA partnership was subsequently awarded a further grant from the HPS for a 20 month mentorship project.

A stakeholder analysis, situational analysis and project planning workshop in 2015, conducted by the RCM/UPMA partnership and all its local stakeholders, resulted in a quality improvement (QI) plan to develop a model of mentorship for Ugandan midwifery (MOMENTUM) using the principles of action research (AR). AR is valuable for systems improvement and the management of change (Coghlan and Casey, 2002; Bridges and Meyer, 2007) and is an appropriate methodology for collaboration to improve maternity care (McKellar and Pincombe, 2010; Deery, 2011). Quality improvement uses repeated PDSA cycles (Plan, Do, Study, Act) (The Health Foundation, 2013) whereas Action Research uses spiral cycles of PAOR (Plan, Act, Observe, Reflect). In reality, both approaches to effecting change are similar and action research is increasingly being used in quality improvement work in low- and middle-income countries (Gilson, 2012). Originally designed as AR, the project was reframed as QI, a methodology more familiar to health professionals in Uganda.

The MOMENTUM project aimed to improve knowledge, skills and attitude among targeted student midwives in Uganda and had three desired outcomes:

1. Increased capacity to develop mentorship standards at the Uganda Nurses and Midwives Council (UNMC).

2. Targeted clinical learning environments utilised to support students' learning.

3. Targeted midwife mentors demonstrating improved mentorship knowledge, skills and attitude in the clinical environment.

This paper will describe and discuss the process of achieving the first outcome: building capacity to develop mentorship standards at the Uganda Nurses and Midwives Council (UNMC).

\section{Methodology}


Developing a national standard for midwifery mentorship in Uganda

\section{Action research cycles}

AR is a spiral process (Koshy et al, 2011) that can be very complex (Deery, 2011). MOMENTUM was planned around 3 cycles of AR and 3 streams of activity: the development of a national standard for practice learning, development of an education module to train midwives as mentors, and improvements in targeted clinical learning sites. These cycles aimed to generate knowledge around mentorship of student midwives in practice settings in Uganda and to produce a replicable model of mentorship for Ugandan midwifery.

The lead Ugandan midwives for each stream were twinned with a volunteer UK midwife in a similar role, thus creating both 'insider' and 'outsider' action researchers (Coghlan and Brydon-Miller, 2014). The theory of change for the wider HPS assumed that through the placement of volunteer UK health professionals in host organisations there would be mutual benefit (DFID, 2016). UK midwives were engaged for the whole length of the project and provided face-to-face mentoring during 2 four-week visits to Uganda and remote contact at least once per month via smart-phone. Ugandan lead midwives visited the UK approximately half-way through the project; the final project evaluation found that this visit was pivotal in achieving success (Adhikari and Nsubuga, 2017).

Each AR/QI cycle started and finished with a workshop, attended by all stakeholders, for reflection on experience, gathering of new information and action planning. It was considered essential that every work-stream informed the other and that the module and standard reflected the reality of midwifery practice in Uganda. To support this process the RCM and UPMA each had a project team that met regularly, both separately and together; RCM staff also visited Uganda 5 times, attending each workshop and conducting serial stakeholder and site visits. UPMA provided a project manager, a monitoring and evaluation officer and financial and administrative support. THET (the grant manager) also provided support from their in-country office and UK staff.

\section{Ethical Issues}

Originally the partnership had planned to seek institutional research board (IRB) ethical approval for MOMENTUM. However, because MOMENTUM was later reframed as a quality improvement (QI) initiative informed by the principles of AR, IRB approval was not sought. In part this was due to the multi-layered and multi-site complexity of the project and the pressure to meet donor timelines; however, the project was also assessed using CHOP's (2015) comparative worksheet and Baily et al's (2006) ethical framework and was found to fit with QI methodology. This change to QI was agreed amongst UPMA, the participating Universities and Training Schools, the UNMC and the Ugandan 
Developing a national standard for midwifery mentorship in Uganda

Ministries of Health and Education and Sports. Despite the decision to reframe the project, ethical issues were addressed. Clear protocols for dealing with distress were put in place with support and supervision available from in-country and remote AR experts. Participants' information was kept confidential and only accessed by project staff. Participants were informed of their right to refuse participation or withdraw from the project at any time without reprisal of the institutions in which they worked or studied. Travel and accommodation expenses for workshops and other visits were paid and refreshments provided. IRB ethical approval was subsequently gained for follow-on qualitative research which will be published separately.

\section{Negotiating access}

Field access has to be negotiated through gate-keepers, takes time and is a continuous process (Donovan, 2006). The final project evaluation suggested that MOMENTUM's success in gaining access to project sites and organisations such as UNMC was largely due to the preceding project (GMTP) that provided space to build trusting relationships (Adhikari and Nsubuga, 2017). However, gaining access still posed challenges. The UNMC is a small organization comprised of a team of a few health professionals supported by legal and administration staff. Access evolved through a series of meetings, formal and informal, in order to establish relationships and build common understanding of the Ugandan systems, the project objectives and the processes by which they would be achieved. Understanding the processes and systems within the organisation is an important step in QI (The Health Foundation, 2013). Originally, only two face to face encounters were planned between the UK and Ugandan twinned midwives but, due to specific difficulties with gaining access to UNMC, two additional face to face opportunities were facilitated with an extra two weeks in Uganda for the UK twin and a 7 day visit of the Ugandan twin to the UK.

The UNMC work-plan and associated budget for the following year had already been set without inclusion of the development of a standard for mentorship. This did not reflect a lack of support for the project as the UNMC ensured representation at a series of events including the official launch of the project and the initial workshop; however, it was constrained by lack of capacity. Making it clear that the UNMC must lead any such work, the Registrar agreed to allocate a senior staff member to twin with a UK counterpart and discuss how such work might evolve. Subsequently, due to maternity leave, a different staff member was nominated and then, due to sickness, the original 'twin' re-joined the project. However, she already had a number of other work-streams in place; roles and responsibilities had to be re-allocated, delaying progress. A communication plan was developed and relevant resources about for mentorship were shared through face to face and 
Developing a national standard for midwifery mentorship in Uganda

virtual contact. Engaging the UNMC chairperson assisted with access. A critical turning point came when the UNMC twin visited the UK in October 2016 and had exposure to regulatory bodies, higher education institutions and maternity care facilities in Northern Ireland and England. She reflected that this allowed her to see, for the first time, how a system of mentorship could work in practice.

\section{Assessing organisational capacity to develop a standard for practice learning}

Two key project outcomes related to the UNMC itself:

1. UNMC staff to have $70 \%$ increased capacity to develop a standard for practice learning

2. UNMC to have developed a completed draft of a national standard for midwifery mentorship

These outcomes would require identification or development of a tool to assess the capacity of a health professional regulatory body to develop standards, and then to measure any subsequent capacity development.

A mixed methods approach was taken to capacity assessment, similar to that of Clark et al's (2016) rapid assessment of health professional regulatory bodies in Cambodia. Firstly, a comprehensive literature search was undertaken to identify any existing capacity assessment tools for health regulatory bodies. Three such tools were found (Benton et al, 2013: Mundia, 2009; Bryan, 2011) but none were specific to the development of professional standards. Therefore, working with all stakeholders and informed by these existing resources, the MOMENTUM team developed two simple tools with UNMC, outlined below in Tables 2, 3 and 4, the combination of which aimed to assess capacity and then to measure progress against the objectives at key points throughout the project. Alongside these tables, the wider project developed or adapted other tools to capture related data; for example, reflective frameworks for midwives and mentors. Information from these tools informed the development of the standard and the project workshops and reports. Secondly, a desktop review was undertaken to better understand the context of maternity care and healthcare regulation in Uganda. Thirdly, a series of site visits took place to conduct key informant interviews with stakeholders. Baseline data was collected in January 2016 through a participatory approach; organisational capacity assessment is usually conducted using participatory methods (Mundia, 2009).

\section{Building capacity for standards development}

For UNMC, institutional strengthening plans were developed cyclically and in partnership, as a part of the wider MOMENTUM project and through individual twinning activities. Workshops, mentoring 
Developing a national standard for midwifery mentorship in Uganda

and technical assistance through twinning, together with opportunities for peer exchange formed the basis of the project design. In the first phase, baseline assumptions were tested: was the achievement of an accredited standard realistic in the time frame of the project given the different work-plans of UNMC and the MOMENTUM project? Could the lack of a UNMC budget to support the work required for the development of the standard be overcome? Would attempts to build capacity rather drain what capacity already existed? In June 2016, as part of the second AR/QI cycle, UNMC reaffirmed its commitment to the project and moved ahead with developing a concept note and roadmap for change which was presented to the UNMC governance council for inclusion in the yearly work-plan.

Terms of reference were then developed for a technical working group (TWG) to lead the development of a standard that would be compliant with UNMC's governance requirements and have equal worth to other professional standards. WHO (2016) exhorts individual countries to strengthen collaborative practices at policy level and to formulate, strengthen and reinvigorate interdisciplinary and multisectoral technical working groups. The TWG comprised key stakeholders including 4 technical and 1 administrative UNMC staff members, senior representatives from three universities or midwifery training schools, the Ministry of Health/UNFPA Country Representative for Midwifery and the President and Project Coordinator from UPMA; a legal officer was also appointed to ensure compliance. UNMC, as the regulator for both nursing and midwifery, charged the TWG with developing a single standard for practice learning, applicable to both cadres. Planned activities of the TWG were to clarify the current registration and re-licensing processes in place for mentors, to conduct a literature review and scoping exercise to identify relevant standards or good practice guides from within Uganda, regionally and across the globe, to hold focus group discussions and interviews with key informants, to request technical assistance from the UK twin and other experts, to visit other countries and contexts to benchmark best practice and to share learning within the TWG and the wider MOMENTUM project. Going forward, the TWG would also need to agree the process by which any subsequently trained mentors would be properly certificated and profiled on the UNMC register.

First and second drafts of the standard were written by the TWG and circulated widely to stakeholders for comment, including the UK twin midwife and the wider MOMENTUM team. Debate arose around the proposed requirement for nurse and midwife mentors to be educated to at least diploma level; as many Ugandan nurses and midwives are only educated to certificate level this would significantly reduce the number of potential mentors and impact on any plans to scale up 
Developing a national standard for midwifery mentorship in Uganda

mentorship nationally. The TWG considered all the points made and after further amendment forwarded the final standard to the full council for consideration and decision.

\section{Table 1: Timeline of significant activities}

\section{Results}

Assessing the impact of organizational capacity building is a complicated process (Intrac, 2008). Measured against the stated objectives, the project was successful in building UNMC's capacity to develop a standard for midwifery mentorship and was extended to include nursing. At a basic level, the UNMC had no work plan or capacity in January 2016 to develop a standard for mentorship and only one officer had experience in standard setting. By December 2016, 5 UNMC staff had a direct involvement in the progress with time and budget allocated. The formation of the TWG ensured the involvement of key stakeholders and beneficiaries in the development process and a draft standard achieved within the prescribed timeframes.

\section{Table 2: UNMC Capacity for midwifery mentorship standard development}

\section{Table 3: Capacity assessment baseline: January 2016}

Table 4: Capacity assessment review: January 2017

Qualitative data from other sources confirms UNMC's capacity development. Focus group data drawn from a number of participants at the final project workshop in April 2017 show that UNMC had drafted a standard for practice learning, were collaborating more with multi-disciplinary stakeholders, were more approachable, had recognised the importance of mentorship as an issue and had listened to 'the midwifery voice'.

During the final project evaluation, the UNMC Quality Assurance manager explained how the project had helped to develop capacity and also acted as a catalyst for other related projects:

'Mentorship is a burning issue for Uganda. My visit to the UK in October 2016 was the turning point. The MOMENTUM workshops had a great input to the standard. We would like a follow-on project for rolling out mentorship... This work has also captured the interest of others'.

\section{Discussion}

Validity and reliability of data collection instruments 
Developing a national standard for midwifery mentorship in Uganda

Adopting existing, validated instruments is preferable to adapting them or creating new ones (Korb, 2012). Ideally new tools should be developed, piloted and tested before use (Norton, 2009); however, this can be difficult with short-term project funding and fixed timescales. The rudimentary capacity assessment instruments developed with UNMC did enable change to be captured and interrater reliability was assured by the same people involved in developing the tools and collecting data over time; however, the instruments measured the capacity of the whole organisation, not personal capacity of UNMC staff members which was the stated programme objective. Self assessment is important in capacity building (Intrac, 2005) but is subject to problems with social desirability biases (Kimberlin and Winterstein, 2008); therefore the collaborative nature of data collection in this project was a strength. All monitoring and evaluation tools used in MOMENTUM were living documents with an opportunity to review and adapt at the beginning and end of each action cycle.

\section{UNMC's readiness for organisational change}

Organisational readiness for change is a multi-level, multi-faceted construct that combines resolve to implement change with share belief in capability to change (Weiner, 2009). UNMC demonstrated resolve to implement change with unswerving support from the registrar who, despite staffing challenges, committed to providing dedicated staff to this project. However, the shared belief regarding capability grew over time, rising sharply after the officer's visit to the UK and subsequent feedback to UNMC. There was also belief in the partnership to provide capability where UNMC had gaps.

\section{Twinning as an instrument for effecting change}

This project adds to the body of knowledge about midwifery twinning as a means to facilitate organisational and personal change. Smith et al (2004) suggest that a twinning partnership model is appropriate for resource limited settings, facilitates the exchange of ideas, and may result in more learning than traditional consulting. Learning from previous experience (Salvage, 2015) MOMENTUM volunteers were competitively recruited and selectively matched with Ugandan counterparts. They all had significant previous experience of working in low-resource settings and several were familiar with Uganda. The twin allocated to the UNMC had extensive experience of healthcare regulation and management in the UK. The UK twin role was complex including aspects of action researcher, mentor, coach, animator, teacher and friend. Twinned pairs were able to provide both insider and outsider information and perspective; this approach to transnational action research has been effective in other settings (Brown and Gaventa, 2008). 
Developing a national standard for midwifery mentorship in Uganda

Communication posed a significant challenge to the twinning relationship. Such a complex project involving many individuals and organisations, different cultures and time zones and unreliable internet connectivity required clear communication strategies, flexibility and persistence. The workload of Ugandan counterparts and the challenges they faced every day, limited communication time. The key to overcoming these challenges was UPMA's project team on the ground in Uganda who made frequent visits to project sites and acted as trouble-shooters when problems arose. Formation of a social media network via Whatsapp was enormously helpful for the project as a whole, though this did not work for UNMC where communication by e mail was preferred.

\section{The role of workshops}

Workshops were pivotal in bringing all participants together to reflect, observe and plan. With an average of 27 attendees, programmes were balanced between planning content carefully and yet leaving space for exploration and emergent ideas. Facilitation was shared between the project management teams, UK and Ugandan twins and external consultants. They were interactive and participatory with singing, dancing and role play. Workshops appeared to create safe space and a community of practice, levelling hierarchies. Action research often creates such communities (Soultana and Stamatina, 2013; Kilbride et al, 2011). Interview data from UNMC's quality assurance manager suggests that the workshops had great significance in the development of the standard, allowing presentation of progress to and feedback from the wider project participants which fed into revisions of the standard.

\section{Additional benefits}

An unintended but welcome consequence of this project was leadership development within UNMC. The ability to manage change is a key aspect of leadership and management (Pashley, 1998). This project demanded significant change within the context of UNMC's competing workload demands and limited staff and resources; however the registrar role-modelled exemplary leadership (Mumford et al, 2016), recognising and articulating the project's importance to the UNMC team, releasing staff for MOMENTUM activities and peer-exchange and making time for regular meetings. He also created the time and space for the twin to participate in meetings and the visit to the UK which directly linked to her professional and personal development (Severinsson, 2014); these behaviours were then observed being replicated by other UNMC staff.

\section{Sustainability and transferability}


Developing a national standard for midwifery mentorship in Uganda

MOMENTUM was a successful project; the final project evaluation (Adhikari and Nsubuga, 2017) found that action research provided an effective methodology to implement this complex health professional capacity building project, with all participants fully engaged in action, reflection and planning cycles. However, the specific aspect of building regulatory body capacity in standard development through action research may not be replicable as a stand-alone intervention because its success was inextricably linked to the wider programme activities and support structures; regulatory changes should not be developed in isolation (Professional Standards Authority, 2015). MOMENTUM's genesis was in the existing long-term professional association twinning partnership. The MOMENTUM community of practice remains strong through a Whatsapp group in which there is still activity nearly every day, 6 months after the project ended. The individual relationship between the UNMC and UK midwife twins is ongoing through e mail and social media; both twins are currently studying for a PhD. The UK twin is now working on a new EU funded mentorship project in Eastern Europe, taking skills and experience from MOMENTUM to a new context.

Encouragingly, the project has been a catalyst for two changes at policy level. Firstly, the Ministry of Health of Uganda, whose support for the RCM/UPMA partnership and the MOMENTUM project has been unswerving, has created a further technical working group for the harmonisation of mentorship tools being used in maternal and newborn care. Secondly, the Ministry of Education and Sports of Uganda plan to include the MOMENTUM model in the new curriculum for nursing and midwifery, currently under development.

Going forward, UNMC has a long-term plan to include mentorship as a mandatory role for midwives in the Scope of Practice. The standards for nursing and midwifery training and practice are being reviewed to enable the implementation of the mentorship standard. The mentorship module, also developed through MOMENTUM, is to be accredited as a CDP module by UNMC with training provided by UPMA; this is the first time that UPMA have been an accredited provider of a UNMC accredited CPD programme. All this is encouraging but the introduction and embedding of new models in health care is complex (Forster et al, 2011) and positive research findings are only one factor in whether the model will be implemented. The project evaluation (Adhikari and Nsubuga, 2017) suggested that MOMENTUM has the potential to be sustainable and rolled out nationally but that the Ugandan team will need support to continue this work until they are ready to move forward independently. This will require ongoing funding. Normalisation Process Theory, which examines the implementation of complex health interventions (Forster et al, 2011), may provide a useful framework for any follow-on intervention. 
Developing a national standard for midwifery mentorship in Uganda

\section{Limitations and lessons learned}

MOMENTUM developed and tested a model of mentorship; data from practice, used to inform the standard, was therefore limited to four clinical pilot sites, all within 3 hours journey from the capital city. However, these did represent government, faith-based and private care provision. New project ideas and initiatives can overburden scarce human resources, particularly in the public sector (Adhikari and Nsubuga, 2017). Whilst MOMENTUM was successful it did considerably increase the workload of UNMC staff who were already over-burdened, and for no additional financial reward.

\section{Conclusions and recommendations}

Regulatory changes should be made in collaboration. Quality improvement and action research can provide frameworks to ensure synergy during such system changes. However, these rely on strong partnership and commitment to relationship at many levels to ensure access to organisations, individuals and project sites. Gaining access is an iterative process. Strong organizational leadership and readiness for change can facilitate successful capacity building. Sufficient time and funding is needed to develop and pilot new instruments and monitoring and evaluation tools. The new capacity assessment tools developed in the project should be tested more widely and validated before further use. Securing appropriate ethical approval for complex action research projects takes time and specific expertise and can be costly.

Midwifery twinning can be a successful strategy for effective organizational and leadership development; however, twins must be carefully selected and matched and clear plans agreed for communication. Repeated placements of short-term international health volunteers within the context of a long-term partnership, with supportive supervision in both home and host countries and with regular virtual contact between placements was effective in delivering the project objectives. Peer exchange visits were pivotal to this success and must be built into project funding. Further research into the reciprocal impact of health volunteering on individuals, their home organisations and the wider health services is needed.

This project has shown that the concept of mentorship to support practice learning for student midwives is transferrable to the Ugandan context; this approach should now be scaled up and efforts made to ensure sustainability of the project's inputs. However, this depends on sufficient qualified and appropriately trained midwives within the Ugandan workforce. Therefore, a programme to address midwifery workforce shortages is recommended as an immediate priority. 
Developing a national standard for midwifery mentorship in Uganda

\section{References}

Adhikari, R. and Nsubuga, F. (2017) MOMENTUM end of project evaluation report, London: RCM,

Baily, M., Bottrell, M., Lynn, J. et al (2006) The ethics of using QI methods to improve healthcare quality and safety, New York: The Hastings Centre

Benton D., González-Jurado M. and Beneit-Montesinos J.(2013), 'Defining nurse regulation and regulatory body performance: a policy Delphi study'. Int Nurs Rev., 60(3):303-12.

Bridges, J., Meyer, J. (2007) 'Exploring the effectiveness of action research as a tool for organizational change in health care', Journal of Research in Nursing, 12(4), pp. 389-399

Brown, D. and Gaventa, J. (2008) Constructing Transnational Action Research Networks: IDS working paper 302. Brighton: Institute of Development Studies

Bryan., T.K (2011). 'Exploring the Dimensions of Organizational Capacity for Local Social Service Delivery Organizations Using a Multi-Method Approach'. Dissertation submitted to the faculty of the Virginia Polytechnic Institute and State University. https://theses.lib.vt.edu/theses/available/etd12182011-102130/unrestricted/Bryan TK D 2011.pdf last accessed June 2017

Cadee, F. et al (2016). 'The state of the art of twinning: a concept analysis of twinning in healthcare', Globalization and Health, 12:66

CHOP (2015) Quality improvement versus research, available at https://irb.research.chop.edu/sites/default/files/documents/quality improvement or research wo rksheet.pdf accessed 14.09.2107

Clarke, D., Duke, J, Wuliji, T. et al (2016) 'Strengthening health professions regulation in Cambodia: a rapid assessment', Human Resources for Health, 14:9

Coggins, J., (2008) 'Strengthening midwifery leadership', RCM Midwives, 8(7):310-3

Coghlan, D. and Casey, D. (2002) 'Action research from the inside', Journal of Advanced Nursing, $35(5), 674-682$

Coghlan, D. and Brydon-Miller, M. (2014) The Sage encyclopaedia of action research, Los Angeles: Sage

DFID (2016) Health Partnership Scheme Evaluation Synthesis Report. London: DFID

Deery, R. (2011) 'Balancing research and action in troubled times: action research as a tool for change’, Evidence Based Midwifery, 9(3): 89-94

Donovan, P. (2006) 'Ethnography' in Cluett, E. and Bluff, R. Principles and practises of research in midwifery $\left(2^{\text {nd }}\right.$. Ed.), Edinburgh: Elsevier

Forster, D. et al (2011) 'Exploring implementation and sustainability of models of care: can theory help?' BMC Public Health, 11(Suppl 5):S8 
Developing a national standard for midwifery mentorship in Uganda

Gilson, L. (2010) 'Action Research' in Gilson L, ed. (2012). Health policy and systems research: a methodology reader. Geneva: Alliance for Health Policy and Systems Research, World Health Organization

Jayanna, $\mathrm{K}$ et al (2016) 'Effectiveness of nurse mentoring in improving quality of institutional births in South India', PLOS ONE, 11(9)

International Confederation of Midwives (2014) 'Twinning as a tool to strengthen midwives associations', available at

http://internationalmidwives.org/assets/uploads/documents/Twinning/140419\%20Twinning\%20IC M\%20V04.pdf accessed 11.09.2017

Hailey, J., James, R. and Wrigley, R. (2005) 'Rising to the challenges: assessing the impacts of organisational capacity building (Praxis Paper), available at

http://dspace.africaportal.org/jspui/bitstream/123456789/21792/1/Rising\%20to\%20the\%20Challen ges\%20Assessing\%20the\%20Impacts\%20of\%200rganisational\%20Capacity\%20Building.pdf?1 accessed 15.09.2017

Kilbride, C., Perry, L., Flatley, M., Turner, E. and Meyer, J. (2011) 'Developing theory and practice: Creation of a Community of Practice through Action Research produced excellence in stroke care', Journal of Interprofessional Care, 25(2): 91-97

Kimberlin, C. and Winterstein, A. (2008) 'Validity and reliability of measurement instruments used in research'. American Journal of Health System Pharmacy, 1;65(23):2276-84

Korb, K. (2012) 'Conducting educational research: adopting or adapting an instrument', available at http://korbedpsych.com/R09aAdopt.html accessed 17.09.2017

Koshy, E., Koshy, V. and Waterman, H. (2011) 'Action research in healthcare', London: Sage

McKellar, L. and Pincombe, J. (2010) 'Action research: a process to facilitate collaboration and change in clinical midwifery practice', Evidence Based Midwifery, 8(3), 85-90

Ministry of Health of Uganda (2013) Mid-term review report of the Health Sector Strategic and Investment Plan 2010/2011-2014/2015. Available at http://library.health.go.ug/publications/healthworkforce-human-resource-management/performance-management/midterm-review-report accessed 11.09.2017

Mumford, M., Hunter, S., Eubanks, D., Bedell, E., and Murphy, S., (2016) 'Developing leaders for creative efforts: a domain-based approach to leadership development'. Human Resource Management Review, 17(4): 402-417

Mundia., M., (2009). Organisational capacity assessment: an introduction to a tool. KEPA. Helsinki, Finland. https://www.kepa.fi/tiedostot/julkaisut/organisational-capacity-assessment.pdf last accessed June 2017

Myall, M., Levett-Jones, T. and Lathlean, J.,(2008) 'Mentorship in contemporary practice: the experiences of nursing students and practice mentors', Journal of Clinical Nursing, 17(14): 1834-42 
Developing a national standard for midwifery mentorship in Uganda

Nabirye, R., Beinempaka, F., Okene, C. et al (2014) 'Improving midwifery care in Ugandan public hospitals: the midwives' perspective', International Journal of Health Professions, 2(1): 7-14

Norton, L. (2009) 'Developing pedagogical research tools' in Action research in learning and teaching. London: Routledge

Pashley, G., (1998) 'Management and leadership in Midwifery', British Journal of Midwifery, 6(7): $460-464$

Professional Standards Authority (2015) Rethinking regulation. London: Professional Standards Authority for Health and Social Care

Royal College of Midwives (2015a) 'Global Midwifery Twinning Project Midwifery needs assessment: Uganda'. Available from global@rcm.org.uk

Royal College of Midwives (2015b) 'Supporting midwifery beyond our borders: the Global Midwifery Twinning Project', available at https://www.rcm.org.uk/global-midwifery-twinning-project-summary accessed 11.09.2017

Royal College of Midwives (2016) 'MOMENTUM Project Baseline Assessment'. Available from global@rcm.org.uk

Royal College of Nursing (2017) 'Helping students get the best from their practice placements: an RCN toolkit', London: RCN

Salvage, J. (2015) Global Midwifery Twinning Partnerships: Final Evaluation. London: RCM

Sayani, A, Jan, R. and Lennox, S. et al (2017) Evaluating the results of mentorship training for community midwives in Sindh, Pakistan, British Journal of Midwifery, 25(8): 511-518

Severinsson, E., (2014).' Capacity building: a challenge for nurse managers', Journal of Nursing Management, 22(4): 407-409

Smith, J., Schecter, K., Shabarova,Z., Posokhova, S., Gozhenko, N., Nizova, N. and Tyapkin, G., Applying a twinning methodology to successfully prevent MTCT in resource-limited settings in Eurasia, available at http://www.aiha.com/wp-content/uploads/2015/07/Twinning-WePeE6713Bangkok.pdf accessed 19.09.017

Soultana, M. and Stamatina, B., (2013) 'Collaborative action research projects: the role of communities of practice and mentoring in enhancing teachers' continuing professional development', Action Researcher in Education, 4:109-121

THET (2016) Health Partnership Scheme. Available at https://www.thet.org/our-work/healthpartnership-scheme/ accessed 11.09.2017

The Health Foundation (2013) Quality improvement made simple. London: The Health Foundation UNFPA (2014) The state of the world's midwifery: a universal pathway, a woman's right to health. Available at http://www.unfpa.org/sowmy accessed 11.09.2017 
Developing a national standard for midwifery mentorship in Uganda

Weiner, B. (2009) 'A theory of organizational readiness for change', Implementation Science, 4:67

West, S., Clark, T. and Jasper, M. (2008) Enabling learning in nursing and midwifery practice: a guide for mentors. Chichester: Wiley

Workneh, G. et al (2013) 'Evaluation of the effectiveness of an outreach clinical mentoring programme in support of paediatric HIV scale-up in Botswana', AIDS Care, 25(1): 11-19

World Bank (2010) Participation and civic engagement. Available at http://web.worldbank.org accessed 13.09.2017

WHO (2016) Global strategic directions for strengthening nursing and midwifery 2016-2020. Geneva: WHO available at http://www.who.int/hrh/nursing midwifery/global-strategicmidwifery2016-2020.pdf accessed 18.09.2017

\section{Acknowledgements}

This project was funded with UK aid from the British people through the Health Partnerships Scheme; this scheme was managed by the Tropical Health and Education Trust. 